\title{
Web3DGIS-Based System for Reservoir Landslide Monitoring and Early Warning
}

\author{
Huang Huang ${ }^{1,2}$, Jianhua $\mathrm{Ni}^{1,2}$, Yu Zhang ${ }^{3}$, Tianlu Qian ${ }^{1,2}$, Dingtao Shen ${ }^{1,2,3}$ and \\ Jiechen Wang $1,2,4, *$ \\ 1 Jiangsu Provincial Key Laboratory of Geographic Information Science and Technology, \\ Nanjing 210023, China; huangyymail@163.com (H.H.); neejianhua@126.com (J.N.); \\ qiantianlu@aliyun.com (T.Q.); shendingtao@aliyun.com (D.S.) \\ 2 Department of Geographic Information Science, Nanjing University, Nanjing 210023, China \\ 3 Changjiang River Scientific Research Institute, Changjiang Water Resources Commission, \\ Wuhan 430010, China; yuzhanggis@163.com \\ 4 Jiangsu Center for Collaborative Innovation in Geographical Information Resource Development \\ and Application, Nanjing 210023, China \\ * Correspondence: wangjiechen@hotmail.com or wangjiechen@nju.edu.cn; Tel.: +86-25-8968-0669; \\ Fax: +86-25-8968-2686
}

Academic Editor: Antonio Fernández-Caballero

Received: 6 November 2015; Accepted: 26 January 2016; Published: 4 February 2016

\begin{abstract}
Landslides are the most frequent type of natural disaster, and they bring about large-scale damage and are a threat to human lives and infrastructure; therefore, the ability to conduct real-time monitoring and early warning is important. In this study, a Web3DGIS (Web3D geographic information systems) system for monitoring and forecasting landslides was developed using the Danjiangkou Reservoir area as a case study. The development of this technique involved system construction, functional design, organizing and managing multi-source spatial data, and implementing a forecasting plan and landslide-forecasting model. By integrating sensor technologies, spatial information technologies, 3D visualization technologies, and a landslide-forecasting model, the results of this study provide a tool for real-time monitoring at potential landslide sites. When relevant data from these sites reach threshold values, the model automatically initiates forecasting procedures, and sends information to disaster prevention sectors for emergency management.
\end{abstract}

Keywords: landslide monitoring; landslide early-warning; natural disasters; Web3DGIS

\section{Introduction}

In recent years, landslides, debris flows, and other natural disasters have been attributed to changes in the global climate, heavy localized rainfall, strong tropical windstorms, and other extreme weather situations. In China, official statistics from the Geographical Research Bureau show that in 2014 there were 10,907 natural disasters, causing 349 deaths and 5.41 billion yuan of damage in direct economic loss. Among these events, landslides were the most frequent, comprising $~ 74.5 \%$ of the total number of natural disasters, and the most severe in terms of damage. Given the threat to human life and infrastructure, minimizing the impact of landslides remains critical. Solutions that have been proposed include transforming the shapes of landslide-risk slopes, structural supports for soil and rock features in landslide areas, and reducing the effects of groundwater and surface water on slope stability. However, while these approaches could decrease the occurrence of landslides, large-scale control remains difficult owing to limitations from construction, available technologies, and cost. Therefore, the ability to conduct real-time monitoring and disaster early warning is critical. 
Landslide stability is affected by both internal and external factors, whose mechanisms vary concurrently; therefore, the main approach to real-time monitoring involves monitoring the state of these inducing factors. Monitoring is focused on either slope surface or subsurface conditions (e.g., groundwater levels and physical composition). Global Positioning System (GPS) techniques were first applied to monitor landslide deformation in the 1990s [1-4], and Zumberge in Jet Propulsion Laboratory put forward the precise point positioning (PPP) technique, anoptimized GPS technique. The PPP technique has taken a dominating role in landslide monitoring [5-7]. In the mid-1990s, Dowding, Kane, and others, introduced Time Domain Reflectometry (TDR) techniques into obtaining landslide deformation data by burying coaxial cables in landslide areas and measuring their changing state $[8,9]$. In the late 1990s and early 2000s, Interferometric synthetic aperture radar, close range photogrammetry measurements, and other techniques were also applied to surface deformation monitoring [10-13]. Accompanied with the development of monitoring techniques, the monitoring sensors experienced rapid development, from simple and relatively independent monitoring instruments (e.g., rainfall gauge, wire extensometers) to professional landslide sensors, which can transfer monitoring data to scene sites set around the landslides (e.g., osmometer, inclinometer), and then to the multi-sensor networks with the ability of real-time remote data transmission $[14,15]$. The efficiency and accuracy of monitoring sensors have been further improved to provide a sound statistical basis for the development of landslide early warning systems. In addition, modern mathematical methods, including grey system and fuzzy math, have also been gradually applied to landslide early warning endeavors [16-19].

The development of geographical information systems (GIS), and network and sensor techniques has provided strong support for the integration, management, and analysis of spatial statistical data regarding landslides. By integrating the above techniques with landslide early warning models, real-time early warning of landslides becomes possible [20-25], as does the design and development of practical monitoring systems [26-28] and disaster handling decision-making and support systems [29-32]. Some progress has been made on the development of an early warning system; however, there are issues that remain to be resolved: (1) expression and analysis of three-dimensional spatial information; (2) real-time collection, transfers, storage, analysis and integration of multi-spot and multi-type sensor statistics; and (3) connecting the landslide early warning modal with a decision-making model and with information publishing functions, so as to effectively achieve the functional integration of the system.

In this study, the Danjiangkou Reservoir area was used as a case study to develop a system monitoring and modeling landslides based on Web3DGIS (Web3D Geographic Information Systems), which features three-dimensional spatial expression and function analysis of the ground surface environmental and monitoring spot data. The developed method, which is based on a real-time data transport network among sensors, on-spot monitoring sites, and monitoring early warning centers, is able to collect and store real-time monitoring data, and to integrate monitoring, early warning, and information publishing functions.

\section{Target Area}

Danjiangkou Reservoir, China (Figure 1), is the largest artificial freshwater lake in Asia, and forms a water source for the South-to-North water diversion project in China. The project's central line was officially launched in late 2003, introducing water from Danjiangkou Reservoir to the Huanghuaihai Plain, which hosts over 20 cities ofvarying size. During construction of the water diversion project, the height of the Danjiangkou dam was extended, and its regular water-storage level was raised from 157 to $170 \mathrm{~m}$, storage capacity increased from 17.45 to 29.05 billion $\mathrm{m}^{3}$, and the water area expanded from 700 to $1022.75 \mathrm{~km}^{2}$. When the reservoir water level rose, original drying landslide fronts were immersed, and stability of rock and soil mass were reduced. Furthermore, hydrodynamic pressure caused by the rapid water level change induced deformation. According to the geological survey results, before the water level rose, there were about 23 landslides with ascale of over 100,000 $\mathrm{m}^{3}$; five years after the water level rose, the number of landslides with ascale of over 100,000 $\mathrm{m}^{3}$ was about 30 . 
To protect human life and infrastructure, the regional management and disaster prevention agencies require real-time monitoring of potential landslide sites, and an early warning system for landslide events in the Danjiangkou Reservoir area.

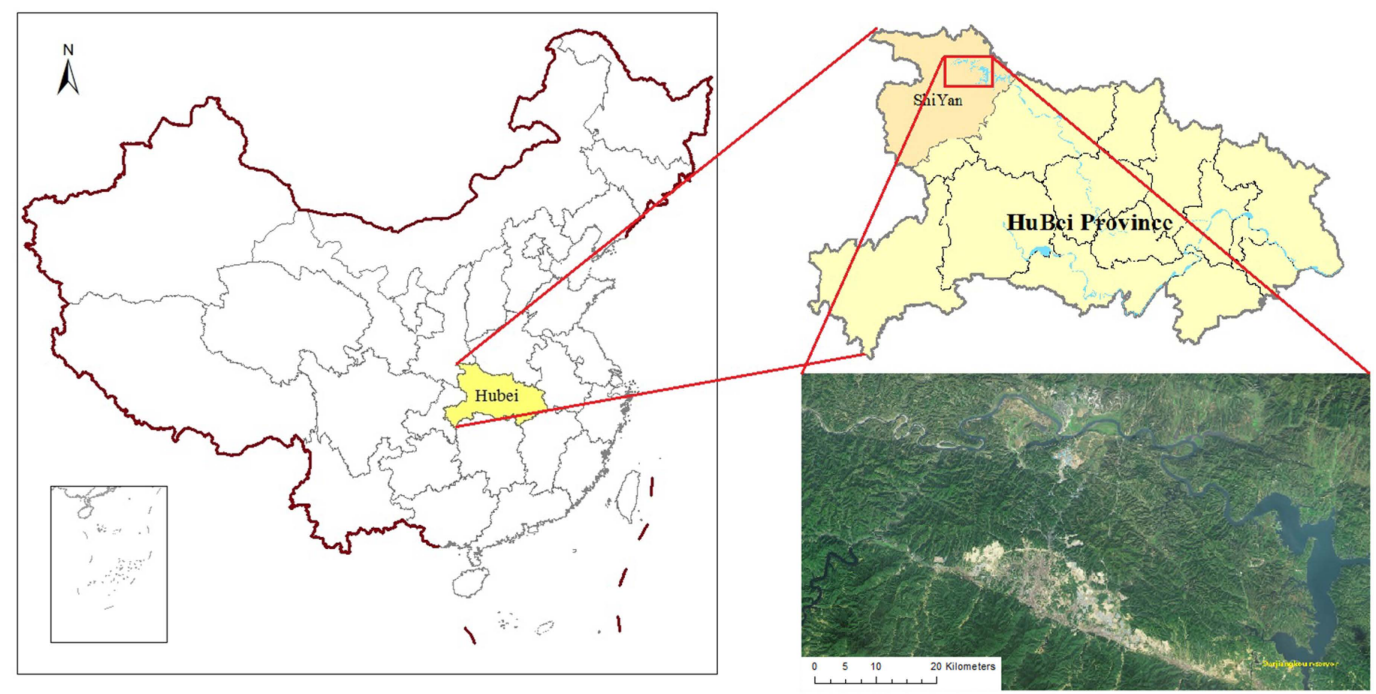

Figure 1. Location of the study area within the northwestern region of Hubei Province, China.

\section{System Structure and Design}

The software structure of the system developed in this study was based on the monitoring database, which is supported by a Brower/Server model with WebGIS and Web3D technologies (Figure 2). Using SQL (Structure Query Language) server, Visual Studio and skyline platform (a 3D GIS application development platform), a multi-structure for application-information and data was constructed, and the service was oriented to different applications, offering convenience for reuse and the expansion of system functions.

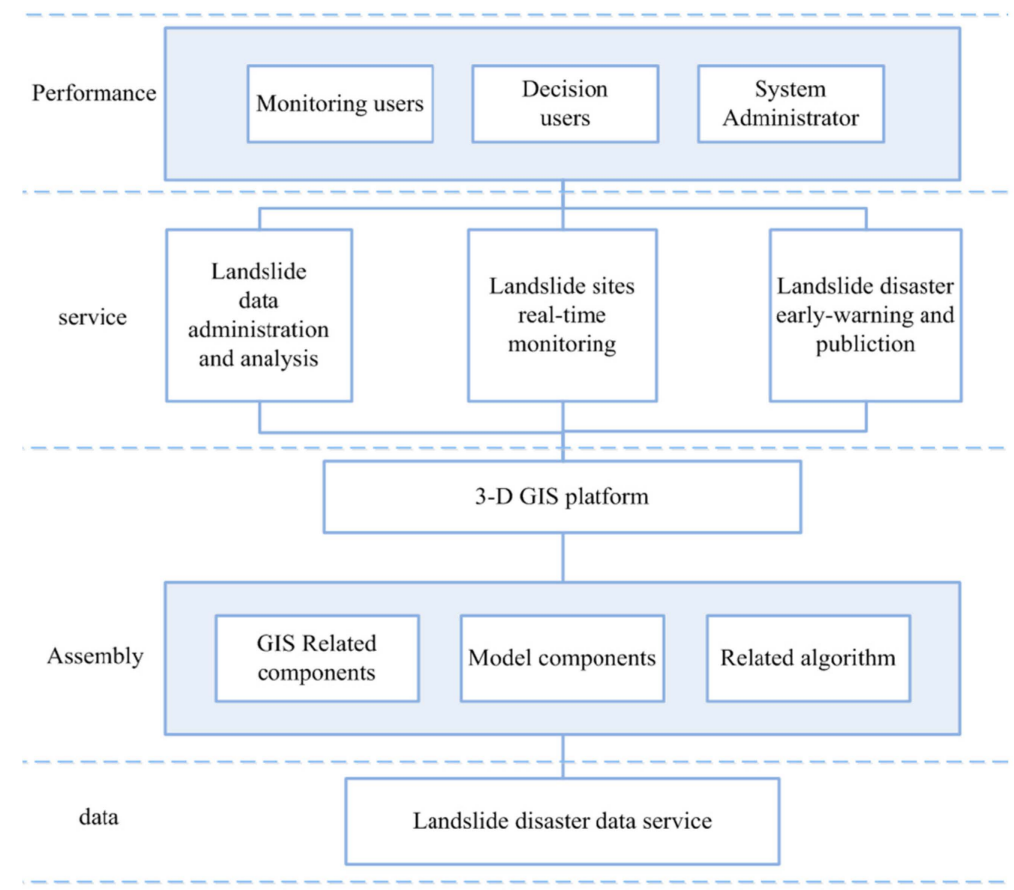

Figure 2. Software structure of the landslide monitoring and early warning system. 
Data storage and management services were integrated into the system, including those for real-time monitoring data, historical monitoring data, rock and soil mass characteristics data, emergency information, and basic geographical data. The assembly level of the system offers components relevant for the operational sector, including the analysis of landslide monitoring data and an early warning module. After the assembly level integration, the service sector offers simple but practical operational services, primarily including three-dimensional spatial analysis, real-time monitoring services, landslide data consulting and management, early warning analysis, a disaster publishing service, and a system management service. The performance sector is responsible for human-computer interaction services and a thematic map-making output service.

According to the operational procedures and application requirements for a landslide early warning service, the system has five main functions:

(1) Collection and management of multiple datasets pertaining to landslides, including fundamental geographical data, real-time and historical monitoring data, acquirement, transfer, preprocessing and management of emergency service data.

(2) Query research and spatial statistical analysis, including comprehensive querying of each monitoring site (e.g., feature, section, and sphere) and statistical analysis of feature data.

(3) Landslide early warning and related information publishing. Based on the features of the potential landslide location and its real-time monitoring data, a model for landslide forecasting and emergency warning that is able to publish potential disaster evaluation information to the public and relevant departments is selected.

(4) Expression and analysis of three-dimensional information, including a three-dimensional depiction of the target area and key monitoring locations. Focused on data relating to flow fields and groundwater level, a combination of functions and needs was developed to address landslide prediction and the evaluation of relevant three-dimensional spatial analysis.

(5) Support functions, including user management, operational right management, data management and maintenance, and other regular functions.

\section{Key Technologies}

\subsection{Multi-Data Organization and Management}

Landslide monitoring and early warning systems involves a large volume of data from different sources and of various types, and with complex relationships between them. They include both static and dynamic real-time monitoring data, lattice and arrow data, and non-spatial data on charts, texts, photos, and videos. In order to guarantee system functionality, a reasonable data model was needed, in which data were effectively organized and managed. This required a number of key technologies to be applied to the construction of the landslide special data pool, and to the organization, transport, and expression of three-dimensional scene data.

\subsubsection{Special Data Pool for Landslide Monitoring}

With regard to data content, the special topics data of landslide monitoring were placed into one of the following five categories (Table 1), while the technological procedures were integrated into the database construction (Figure 3). 
Table 1. Landslide Monitoring Data Categories.

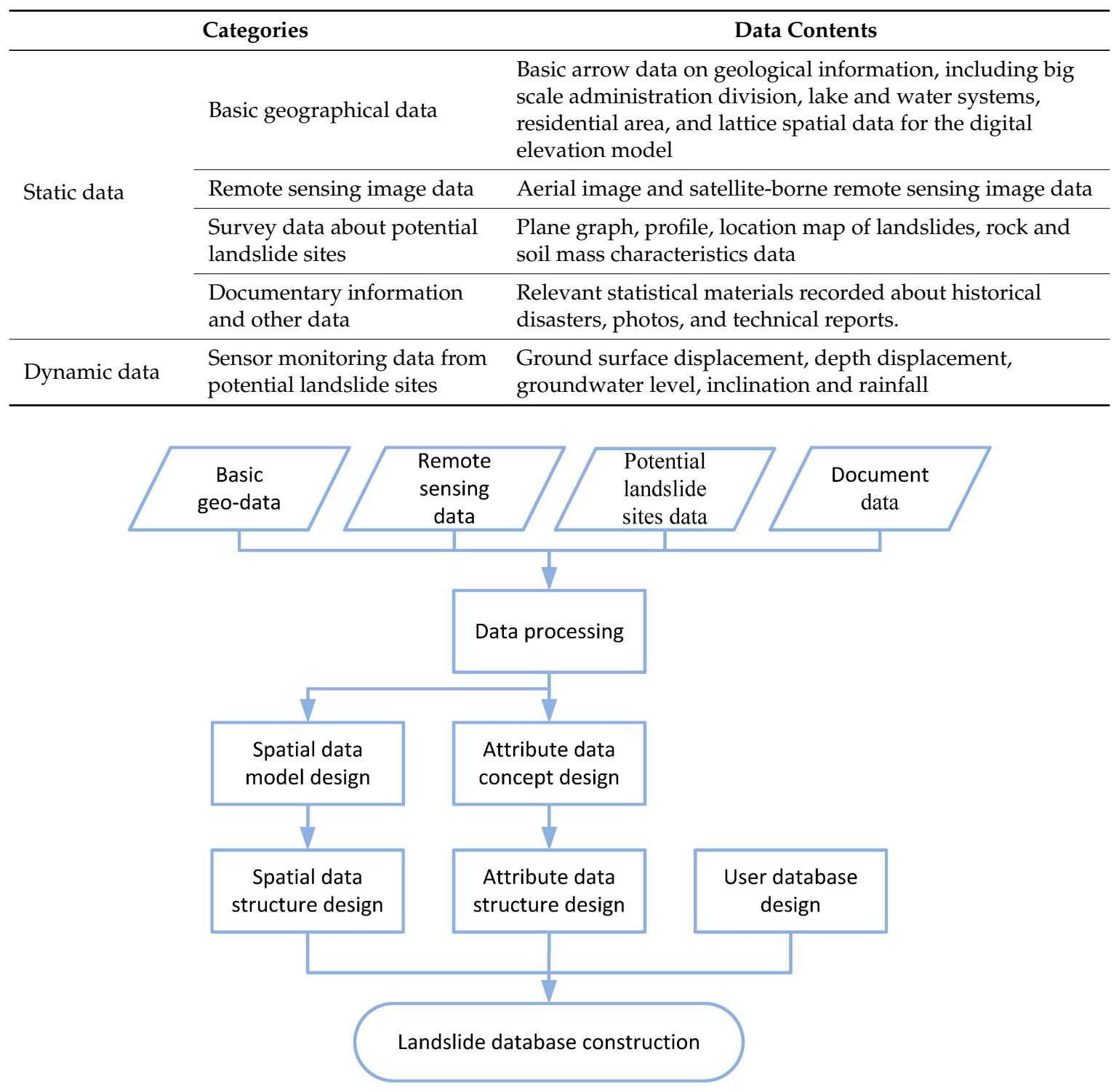

Figure 3. Flow-chart of database construction.

With the spatial database and spatial data engine, the spatial data form an object oriented database management system, which has integrated management over spatial data and attribute data. For the design of spatial databases, previous studies have investigated landslide features in-depth using an object-oriented information model and a design method for a structured UML static view. Using this approach, they obtained the relationships between the patterns of landslide information management, countermeasures, and limitations. The spatial data of potential landslides include dotted and polygon maps, unified serial numbers (id) for monitoring sites, influential areas, and boundaries.

The attribute data of potential landslides involve large volumes and contain complex relationships, primarily for those relating to real-time monitoring, forecasting and early warning, historical information, and monitoring management over relevant staff. The real-time monitoring data include landslide monitoring information, real-time monitoring sites, and sensors, among which various relationships exist (Figure 4). 


\begin{tabular}{|c|c|c|}
\hline History monitor data table & \multirow{5}{*}{\begin{tabular}{|l}
\multicolumn{1}{|c}{ Sensor table } \\
$\underline{\text { sensor code }}$ \\
sensor name \\
Monitoring site code \\
Scene site code \\
Sensor coordination \\
item code \\
Install time \\
Test time \\
Note
\end{tabular}} & \multirow{6}{*}{$\begin{array}{l}\quad \text { Scene site table } \\
\text { Scene site code } \\
\text { Monitoring site code } \\
\text { Monitoring site type } \\
\text { location } \\
\text { Height } \\
\text { Install time } \\
\text { Test time } \\
\text { Scene site type } \\
\text { Local port number } \\
\text { Remote port number } \\
\text { The remote IP } \\
\text { Communication port number } \\
\text { Timed out waiting time } \\
\text { Weather feature description }\end{array}$} \\
\hline $\begin{array}{l}\text { Sensor code } \\
\text { Collection time } \\
\text { value } \\
\text { description }\end{array}$ & & \\
\hline & & \\
\hline Current monitor data table & & \\
\hline Sensor code & & \\
\hline $\begin{array}{l}\text { value } \\
\text { description }\end{array}$ & $\downarrow$ & \\
\hline Single monitoring item model & Monitoring item table & $\downarrow$ \\
\hline Sensor code & item code & landslide point table \\
\hline $\begin{array}{l}\text { item code } \\
\text { Weigh value } \\
\text { Parameter1 } \\
\text { Parameter2 } \\
\text { Alert lever }\end{array}$ & $\begin{array}{l}\overline{\text { item name }} \\
\text { Value upper limit } \\
\text { Value lower limit } \\
\text { Value unit } \\
\text { Note }\end{array}$ & $\begin{array}{l}\text { landslide point code } \\
\text { landslide point name } \\
\text { Scene site code } \\
\text { landslide type } \\
\text { introduction }\end{array}$ \\
\hline
\end{tabular}

Figure 4. Entity Relationship Diagram of real-time monitoring data model.

\subsubsection{Three-Dimensional Scene Data Organization}

In order to establish an accurate image of the target area, researchers need to integrate remote image data with the digital elevation model, overlapped with multiple geological factors, so as to allow functions including browse, cruise, consultancy, measurement, and analysis in a three-dimensional space. The main data for three-dimensional scene construction are from highly accurate digital evaluation models and high-resolution digital orthophoto maps, whose data are normally restored in the form of a lattice. As a direct three-dimensional display can severely affect system effectiveness and due to the difficulties of achieving real time-mapping of the three-dimensional scene, this study combined the tile pyramid model method with a linear quad-tree index in order to preprocess and reorganize the data needed for the scene [33].

The pyramid model contains multiple resolution levels (Figure 5). When constructing the pyramid, the original lattice data (e.g., the digital evaluation model or remote image) is first set to the bottom (No. 0 level) of the pyramid tile matrix. Based on the No. 0 level, every $2 \times 2$ lattice unit combines together into one unit to form the 1 level lattice matrix. This process is then repeated to form the whole tile pyramid [34].

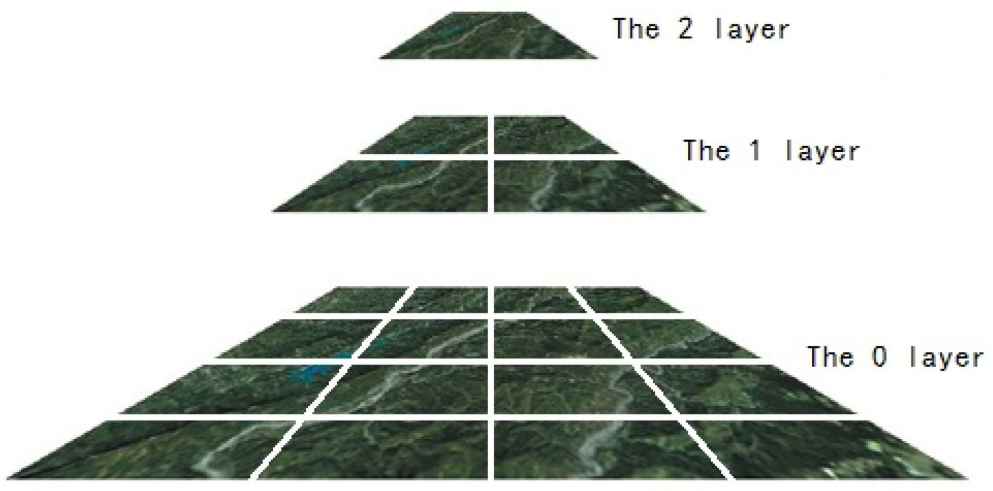

Figure 5. Image tile pyramid model. 
A quad-tree is a tree structure with up to 4 branches in each non-leaf node [33]. It is also a hierarchical data structure, featuring spatial interconnection rescission. The quad-tree structure offers convenience for the index and management of tile data. Based on tile pyramid, the construction of quad-tree index can be divided into three steps: logical partitioning, node coding, and physical partitioning. After partitioning, a topological relationship between tiles is built, which includes two aspects: a neighboring link of the same level and higher, and lower relationships (e.g., that of parents and their children).

The above method can, to a great extent, satisfy the need to visualize a three-dimensional scene in a large area; therefore, it can greatly improve the display effectiveness of the system. This is primarily because cutting out topographical data from outside of the view and using a fast tile search method based on resolution rate greatly reduces the amount of data described in a scene. While mapping the scene, for the specific display proportion, data from the digital elevation model and the image texture of a specific pyramid level (the closest to the display resolution rate) are directly used in the rapid representation of the three-dimensional surface.

After considering the Browser/Server structure of the system, users can set a client-oriented browser and a quick three-dimensional display of related data. To ensure a fluent display of the three-dimensional scene, this study adopted several measures, including a seamless network and the effective transmission of three-dimensional data. Once the initial image is accepted by the user in a low-resolution state, the client displays the three-dimensional data, without waiting for the full transmission of data. Using a distribution system and load balance technology, different servers in different areas can share the burden of three-dimensional data collection; thus, automatically distributing load among all applicable servers.

\subsection{Landslide Forecasting Model}

A landslide-forecasting model must determine the time that a landslide reaches its accelerated deformation-instability phase. The stability of a landslide is affected by internal factors (e.g., landslide shape, soil/rock mechanical parameters) and external factors (e.g., groundwater level, rainfall, and human construction work), which not only have different effects on the landslide, but are also constantly changing.

At present, models for forecasting the time of landslide instability include the Saito Model, creep-spline Combined Model, Verhulst Model, the grey Model $(1,1)$ and so on [35-38]. Each model describes the relationship between instability time and deformation values and velocity, as estimated by the surface conditions, and is able to predict when a landslide will enter the accelerating deformation-instability phase. However, for large areas, we have to set many landslides monitoring sites independently, so using a single forecasting model is not sufficient. In this study, three models were selected: a landslide deformation forecasting, non-linear dynamics model; a grey forecasting model that varies with different periods; and a multi-factor grey forecasting model. These models are respectively responsible for short-term forecasting of relatively unstable landslides, long-middle term forecasting of relatively stable landslides, and forecasting landslides easily affected by external factors. In detail:

(1) Non-linear dynamics model. By nature, landslides are a non-linear dynamic systems controlled by soil and rock conditions (e.g., topography, groundwater, rainfalls, and human engineering). The non-linear dynamics model has long been used [39,40], and has been developed to reach a high level of accuracy in the short-term prediction of landslides. This study applied the non-linear dynamics model proposed by Qin et al. [19], which makes predictions based on three major factors: stress, landslide displacement, and groundwater.

(2) Grey forecasting model. This model, proposed by Deng, is a method for forecasting systems with uncertain factors [38]. By collecting slices of incomplete information, this model was built to consider a long-term general description of a system's development. Luan et al. [41] used this method to monitor and forecast ground surface deformation, and since then it has been 
commonly used in landslide forecasting [42-44]. In this study, the grey model was combined with a time sequence analysis model, such that after amendment of the residual model in time sequence, it was able to forecast trends of uniform motion-accelerating motion, accelerating motion-uniform motion, slow change-uniform motion, and slow change-accelerating motion. Through extraction of the items, which shock periodically, the model can greatly offset influences from external factors.

(3) Multi-factor grey forecasting model. This model, from the perspective of both internal and external factors that can affect landslide deformation, regards the whole landslide as the production of multiple affecting factors. The description of internal affecting factors are modeled after a tendency grey model that varies with different periods, while external affecting factors can be divided into several independent but related linear factors. By combining the model with internal and external factors, a multiple and combined model is constructed and can be used for grey forecasting [45]. The multi grey model considers both external and internal factors relating to deformation, and when these change, the deformation value can be estimated as a fixed quantity. The model is suitable for forecasting landslide deformation affected by external factors (e.g., rainfall and groundwater level).

\section{System Completion}

\subsection{Sensors Deployment}

The landslide monitoring and early warning system developed in this study was deployed at the Danjiangkou Reservoir. Based on past disaster information, 31 potential landslide sites were selected and the responsible department constructed monitoring sites, which were fitted with a rainfall gauge, inclinometer, water level gauge, osmometer and displacement gauge whose real-time information was transmitted to the monitoring and early warning center using GPRS wireless signal transmitter. The deployment of multi-sensors is shown in Figure 6.

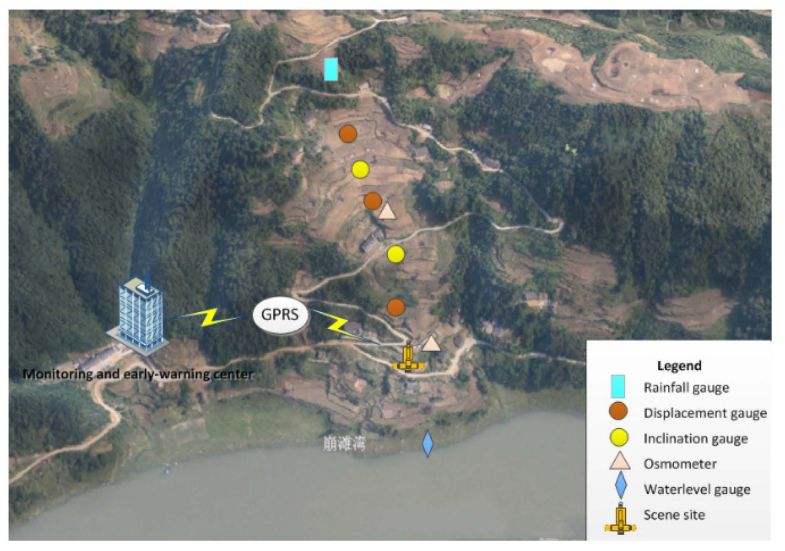

(a)

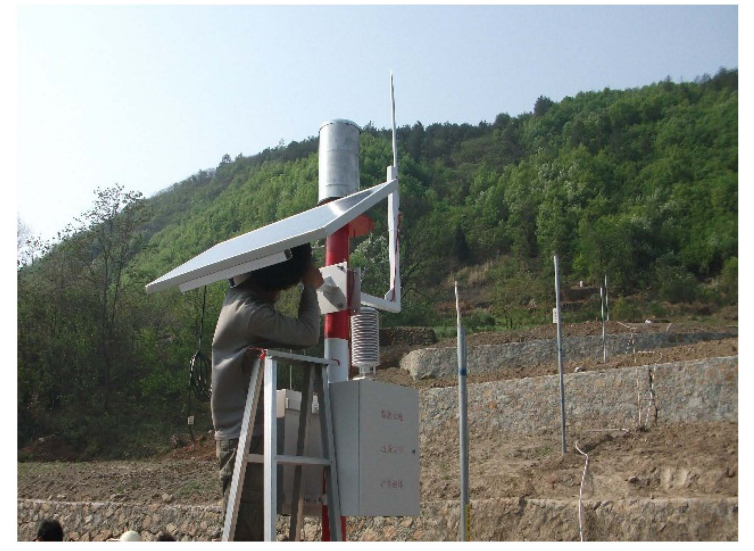

(b)

Figure 6. (a) The sensors network in one of the landslide; and (b) the deployment of sensors.

\subsection{Software System Completion}

The integrated structure of the early warning software system includes a Brower/Server structure, subdivided into the server end and customer end, designed and developed in a .NET structure (a Microsoft XML web services development platform). The server end was completed in the Java programming language and its database is managed by SQL Serve. The server end was mainly developed through JavaScript and FLEX on the skyline three-dimensional digital earth platform, which is able to rapidly construct a simulated three-dimensional scene using large volumes of remote 
image data, digital elevation data, and two- and three-dimensional data. The system, topography of the integrated target area, and the image data with multiple attributes are used to construct the three-dimensional model, which then allows for various functions of contour line analysis, slope analysis, ground surface runoff analysis, section analysis, and other three-dimensional space analysis and expression procedures. The system interface is shown in Figure 7.

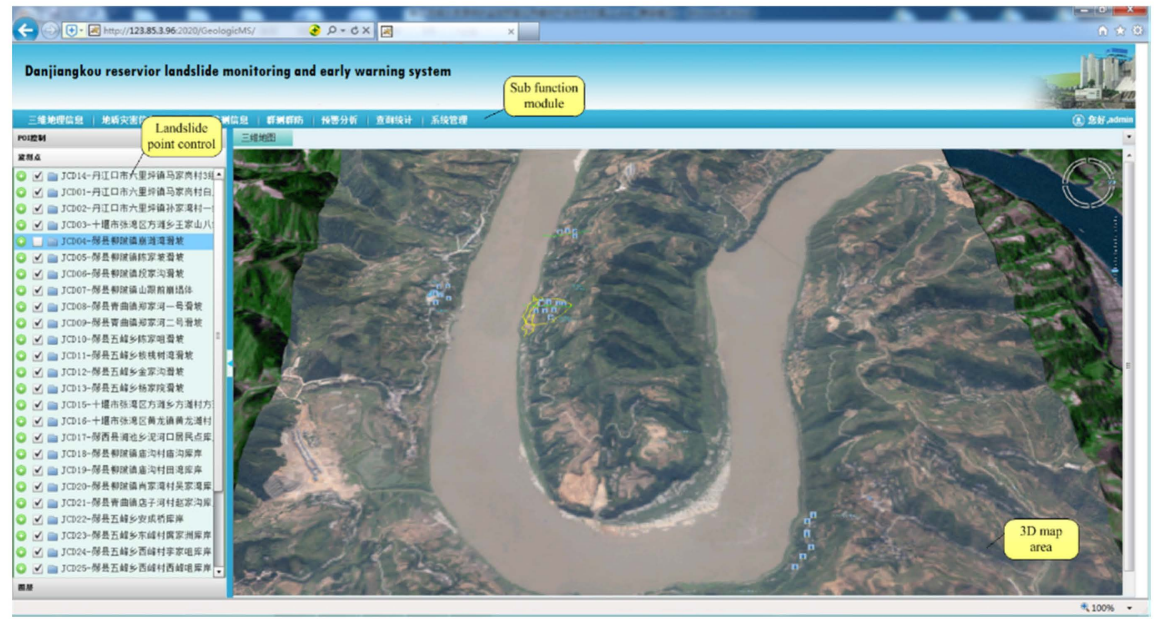

(a)

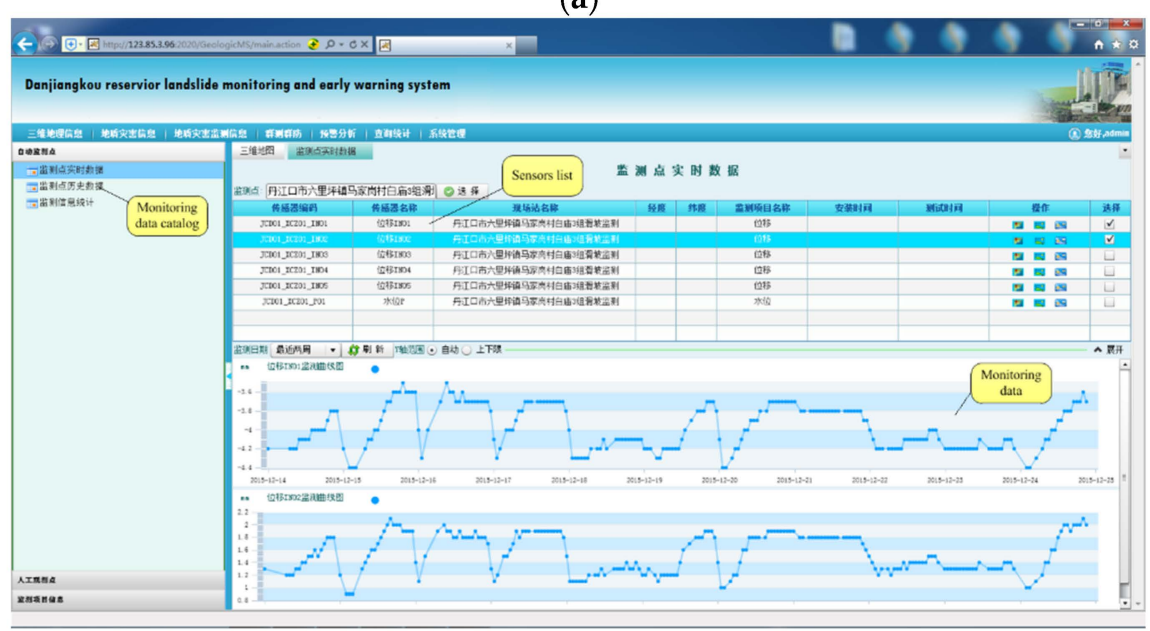

(b)

Figure 7. System interface: (a) the 3D map page; (b) the monitoring data page.

\subsection{Early Warning Completion}

For every single landslide monitoring sites, we analyzed the relationship between rainfall, deformation value/velocity and landslide, then set the threshold for starting landslide forecasting at this site according to the analysis result. When certain data streams change and meet the threshold value, the system automatically initiates its landslide early warning procedure.

By combining past and new real-time monitoring data with deformation early warning conditions (e.g., accumulated accelerated speed, rainfall, and groundwater level), the system can automatically select an appropriate early warning model and calculate the landslide transformation trend and instability time. After observing the calculation results, the system can automatically transmit relevant forecasting information to target users (e.g., disaster control experts and monitoring supervisors). After checking the monitoring data with experts, the system finally determines whether or not to publish the warning information, at which point it will transmit the relevant emergency plan and action suggestions to target people at disaster sites. In summary, this model integrates both the early 
warning results and expert experience, so as to ensure that the published information is as accurate as possible in order to avoid negative social influences from model flaws (Figure 8).

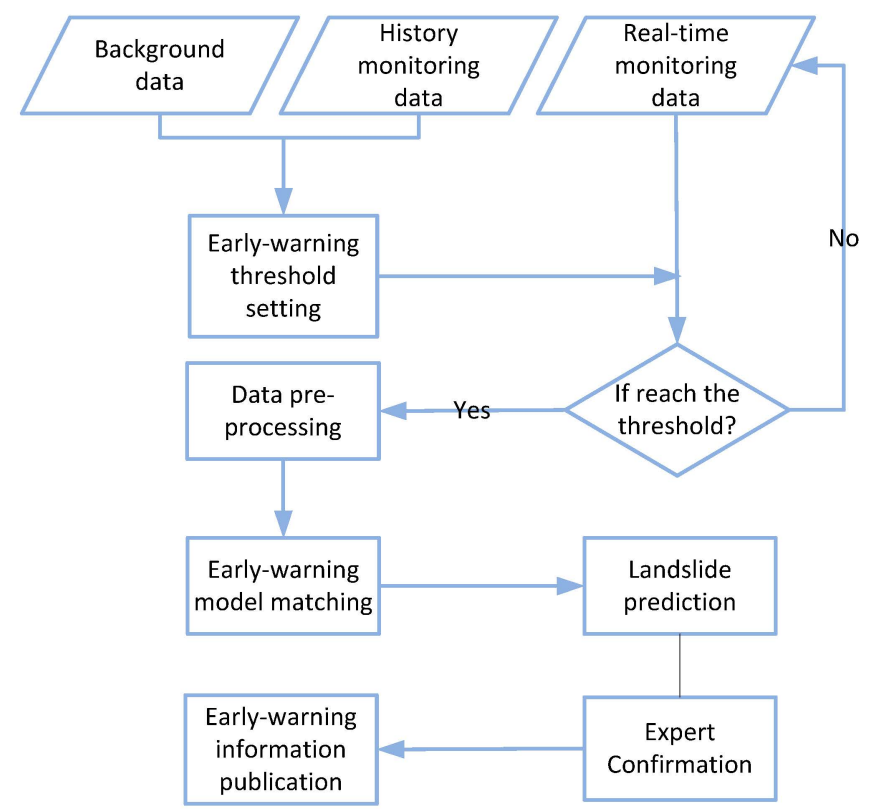

Figure 8. Flow-chart of landslide early warning system.

\section{Conclusions}

This study focused on the development of a landslide monitoring and early warning system in the Danjiangkou Reservoir area, China. The proposed real-time disaster forecasting system is based onWeb3DGIS and uses analysis results from landslide monitoring data and linked forecasting models. After reviewing local conditions and historical landslide data, we set up 31 landslide monitoring sites around the Danjiangkou Reservoir in order to collect data on surface displacement, rainfall, and groundwater. After receiving the data, the system consults the early warning model and information from experts before deciding whether to issue timely disaster information to decision-makers and emergency personnel. The system incorporates many technologies, including those of the sensors, WebGIS, three-dimensional visualization, and landslide forecasting. The final systems offers: (1) a comprehensive combination of multi data and landslide forecasting models that support forecasting accuracy; (2) real-time data collection by different sensors and timely wireless data transmission; and (3) Web3DGIS technology for three-dimensional analysis and expression of spatial information, allowing it to accurately identify the environmental conditions at the monitoring site, and to support the analysis of relevant three-dimensional space.

Acknowledgments: This work was supported by the National Natural Science Foundation of China (Grant Nos. 41501558 and 41571377).

Author Contributions: Huang Huang, Jianhua Ni and Yu Zhang conducted the primary experiments, cartography and analyzed the results. Yu Zhang and Tianlu Qian offered data support for this work. Jiechen Wang and Dingtao Shen provided the original idea for this paper.

Conflicts of Interest: The authors declare no conflict of interest.

\section{References}

1. Mantovani, F.; Soeters, R.; van Westen, C.J. Remote sensing techniques for landslide studies and hazard zonation in Europe. Geomorphology 1996, 15, 213-225.

2. Gili, J.A.; Corominas, J.; Rius, J. Using Global Positioning System techniques in landslide monitoring. Eng. Geol. 2000, 55, 167-192. 
3. Squarzoni, C.; Delacourt, C.; Allemand, P. Differential single-frequency GPS monitoring of the La Valette landslide (French Alps). Eng. Geol. 2005, 79, 215-229. [CrossRef]

4. Xiao, R.; He, X. Real-time landslide monitoring of Pubugou hydropower resettlement zone using continuous GPS. Nat. Hazards 2013, 69, 1647-1660.

5. Palmerini, G. Capabilities of the GNSS precise point positioning technique for landslide monitoring. Disaster Adv. 2012, 5, 509-513.

6. Wang, G.Q. Millimeter-accuracy GPS landslide monitoring using Precise Point Positioning with Single Receiver Phase Ambiguity (PPP-SRPA) resolution: A case study in Puerto Rico. J. Geod. Sci. 2013, 3, $22-31$.

7. Yigit, C. Experimental assessment of post-processed kinematic Precise Point Positioning method for structural health monitoring. Geomat. Nat. Hazards Risk 2014, 7. [CrossRef]

8. Dowding, C.H.; Huang, F.C. Early detection of rock movement with time domain reflectometry. J. Geotech. Eng. 1994, 120, 1413-1427. [CrossRef]

9. Kane, W.F.; Perez, H.; Anderson, N.O. Development of Time Domain Reflectometry System to Monitor Landslide Activity; Final Report, FHWA/CA/TL-96/09; Federal Highway Administration: Washington, DC, USA, 1996.

10. Fruneau, B.; Achache, J.; Delacourt, C. Observation and modelling of the Saint-Etienne-de-Tinée landslide using SAR interferometry. Tectonophysics 1996, 265, 181-190.

11. Carnec, C.; Delacourt, C. Three years of mining subsidence monitored by SAR interferometry, near Gardanne, France. J. Appl. Geophys. 2000, 43, 43-54.

12. Ohnishi, Y.; Nishiyama, S.; Yano, T.; Matsuyama, H.; Amano, K. A study of the application of digital photogrammetry to slope monitoring systems. Int. J. Rock Mech. Min. Sci. 2006, 43, 756-766. [CrossRef]

13. Atzeni, C.; Barla, M.; Pieraccini, M.; Antolini, F. Early Warning Monitoring of natural and engineering slopes with Ground-based Synthetic Aperture Radar. Rock Mech. Rock Eng. 2015, 48, 235-236.

14. Angeli, M.G.; Pasuto, A.; Silvano, S. A critical review of landslide monitoring experiences. Eng. Geol. 2000, 55, 133-147. [CrossRef]

15. Ramesh, M.V. Real-time wireless sensor network for landslide detection. In Proceedings of the Third International Conference on Sensor Technologies and Applications, SENSORCOMM'09, Athens, Greece, 18-23 June 2009; pp. 405-409.

16. Xia, Y. Grey System Prediction Model of Landslide and Its Application. Chin. Sci. Abstr. Ser. B 1995, $14,74$.

17. Chen, H.W.; Chang, N.B. Prediction analysis of solid waste generation based on grey fuzzy dynamic modeling. Resour. Conserv. Recycl. 2000, 29, 1-18.

18. Chung, C.J.F.; Fabbri, A.G. Probabilistic prediction models for landslide hazard mapping. Photogramm. Eng. Remote Sens. 1999, 65, 1389-1399.

19. Qin, S.; Jiao, J.J.; Wang, S. A nonlinear dynamical model of landslide evolution. Geomorphology 2002, 43, 77-85.

20. Carrara, A.; Guzzetti, F.; Cardinali, M.; Reichenbach, P. Use of GIS technology in the prediction and monitoring of landslide hazard. Nat. Hazards 1999, 20, 117-135.

21. Zan, L.; Latini, G.; Piscina, E.; Polloni, G.; Baldelli, P. Landslides early warning monitoring system. In Proceedings of the 2002 IEEE International Geoscience and Remote Sensing Symposium, IGARSS'02, Honolulu, Hawaii, USA, 25-30 July 2002; Volume 1, pp. 188-190.

22. Yin, Y.; Wang, H.; Gao, Y.; Li, X. Real-time monitoring and early warning of landslides at relocated Wushan Town, the Three Gorges Reservoir, China. Landslides 2010, 7, 339-349.

23. Gao, H.X.; Yin, K.L. Study on spatial prediction and time forecast of landslide. Nat. Hazards 2014, 70, 1735-1748.

24. Barla, M.; Antolini, F. An integrated methodology for landslides early warning systems. Landslides 2015, 1-14. [CrossRef]

25. Costanzo, S.; Di Massa, G.; Costanzo, A.; Morrone, L.; Raffo, A.; Spadafora, F.; Borgia, A.; Formetta, G.; Capparelli, G.; Versace, P. Low-cost radars integrated into a landslide early warning systems. Adv. Intell. Syst. Comput. 2015, 354, 11-19.

26. Huang, R.; Huang, J.; Ju, N.; He, C.; Li, W. WebGIS-based information management system for landslides triggered by Wenchuan earthquake. Nat. Hazards 2013, 65, 1507-1517.

27. Mao, S.J.; Liu, Q.X.; Li, M. Design and development of safety production management information system based on a digital coalmine. Procedia Earth Planet. Sci. 2009, 1, 1121-1127. 
28. Intrieri, E.; Gigli, G.; Mugnai, F.; Fanti, R.; Casagli, N. Design and implementation of a landslide early warning system. Eng. Geol. 2012, 147, 124-136.

29. Zerger, A.; Smith, D.I. Impediments to using GIS for real-time disaster decision support. Comput. Environ. Urban Syst. 2003, 27, 123-141.

30. Yu, F.C.; Chen, C.Y.; Lin, S.C.; Lin, Y.C.; Wu, S.Y.; Cheung, K.W. A web-based decision support system for slopeland hazard warning. Environ. Monit. Assess. 2007, 127, 419-428. [PubMed]

31. Chang, K.T.; Wan, S.; Lei, T.C. Development of a spatial decision support system for monitoring earthquake-induced landslides based on aerial photographs and the finite element method. Int. J. Appl. Earth Obs. Geoinform. 2010, 12, 448-456. [CrossRef]

32. Giardino, M.; Perotti, L.; Lanfranco, M.; Perrone, G. GIS and geomatics for disaster management and emergency relief: A proactive response to natural hazards. Appl. Geomat. 2012, 4, 33-46.

33. Finkel, R.A.; Bentley, J.L. Quad trees a data structure for retrieval on composite keys. Acta Inform. 1974, 4, 1-9.

34. Heeger, D.J.; Bergen, J.R. Pyramid-based texture analysis/synthesis. In Proceedings of the 22nd Annual Conference on Computer Graphics and Interactive Techniques, Los Angeles, CA, USA, 9-13 August 1995; pp. 229-238.

35. Saito, M. Forecasting time of slope failure by tertiary creep. In Proceedings of the 7 th International Conference of Soil Mechanics and Foundation Engineering, Mexico City, Mexico, 5-7 May 1969; pp. 677-683.

36. Zhou, C.B.; Zhang, H. A creep-spline combined model and its application to the time prediction of landslides. J. Nat. Disasters 1996, 5, 60-67.

37. Li, T.B.; Chen, M.D. Time prediction of landslide using verhulst inverse-function model. J. Geol. Hazards Environ. Preserv. 1996, 3, 13-17.

38. Deng, J.L. Control problems of grey systems. Syst. Control Lett. 1982, 1, 288-294.

39. Haigh, M.J. Dynamic Systems Approaches in Landslide Hazard Research; Zeitschrift für Geomorphologie; Supplementbände; Schweizerbart science publishers: Stuttgart, Germany, 1988; Volume 67, pp. 79-81.

40. Phillips, J.D. Instability and chaos in hillslope evolution. Am. J. Sci. 1993, 293, 25.

41. Luan, Y.Z.; Jiang, Y.; Jia, M.H. Forecasting the ground subsidence in mine area by grey system. Site Investig. Sci. Technol. 1990, 5, 45-48.

42. Li, X.H.; Jin, X.G.; Kang, H.M.; Lu, Y.; Yang, X.H. Application of GM $(1,1)$ Majorized Model to Simulation-forecast of Landslide. J. Mt. Sci. 2001, 19, 265-269.

43. Lu, P.; Rosenbaum, M.S. Artificial neural networks and grey systems for the prediction of slope stability. Nat. Hazards 2003, 30, 383-398.

44. Li, X.; Kong, J.; Wang, Z. Landslide displacement prediction based on combining method with optimal weight. Nat. Hazards 2012, 61, 635-646. [CrossRef]

45. Wang, X.; Niu, R. Landslide intelligent prediction using object-oriented method. Soil Dyn. Earthq. Eng. 2010, $30,1478-1486$.

(C) 2016 by the authors; licensee MDPI, Basel, Switzerland. This article is an open access article distributed under the terms and conditions of the Creative Commons by Attribution (CC-BY) license (http://creativecommons.org/licenses/by/4.0/). 